\title{
ВПЛИВ ОЖИРІННЯ НА ПЕРЕБІГ ТА ПРОГНОЗ ГОСТРОГО ПАНКРЕАТИТУ
}

\author{
О. І. Дронов ${ }^{1,2}$, І. О. Ковальська ${ }^{1,2}$, К. О. Задорожна², А. І. Горлачач,2 \\ ${ }^{1}$ Національний медичний університет імені О. О. Богомольця МОЗ України, м. Київ, \\ ${ }^{2}$ Київський міський центр хірургії захворювань печінки, підшлункової залози та жовчних шляхів імені В. С. Земскова

\section{IMPACT OF OBESITY ON THE COURSE AND PROGNOSIS OF AN ACUTE PANCREATITIS} \\ O. I. Dronov ${ }^{1,2}$, I. O. Kovalska ${ }^{1,2}$, K. O. Zadorozhna, ${ }^{1,2}$, A. I. Gorlach ${ }^{1,2}$ \\ ${ }^{1}$ Bogomolets National Medical University, Kyiv, \\ ${ }^{2}$ Kyiv Municipal Surgical Centre for the Diseases of Liver, Pancreas and Biliary Ducts named after V. S. Zemskov
}

\begin{abstract}
Реферат
Вступ. Ожиріння є фактором ризику виникнення гострого панкреатиту (ГП). Сьогодні аналіз несприятливого впливу ожиріння на тяжкість перебігу та прогноз ГП не застосовують на практиці для прогнозування та оптимізації лікувальної тактики.

Мета дослідження: проаналізувати вплив індивідуальних параметрів ожиріння на тяжкість перебігу ГП.

Матеріали і методи. Проведений проспективний аналіз результатів лікування 30 хворих з приводу ГП. Досліджене співвідношення індивідуальних параметрів ожиріння за даними комп'ютерної томографії (КТ) та тяжкості перебігу ГП, його локальних та системних ускладнень.

Результати. Найбільш значуща кореляція встановлена між площею вісцерального жиру і електронним індексом маси тіла (elMT) та тяжкістю синдрому поліорганної недостатності (СПОН), тривалістю SIRS (systemic inflammatory response syndrome), тяжкістю локальних ускладнень за шкалою Balthazar. На основі результатів кореляційного аналізу відзначено, що найбільше на тривалість лікування хворих у стаціонарі впливали тривалість SIRS, тяжкість СПОН, КT індекс тяжкості за Balthazar. На основі мультиваріантного аналізу, єдиним параметром, що впливає на тривалість лікування хворого у стаціонарі, є тривалість SIRS, решта параметрів, в тому числі індивідуальні параметри ожиріння, на цей показник не впливали. У хворих при ожирінні достовірно частіше виявляли інфікування скупчень рідини в поєднанні з інфікуванням вогнищ некрозу порівняно з такими у хворих за збільшеної та нормальної маси тіла, проте, у них частіше спостерігали формування псевдокіст підшлункової залози ( $<<0,05)$. При дослідженні інфрікування скупчень рідини і вогнищ некрозу достовірно частіше інфрікування спостерігали у хворих при ожирінні. У пацієнтів при ожирінні спостерігали більш раннє інфрікування скупчень рідини і вогнищ некрозу $(p=0,006)$.

Висновки. Ожиріння є фактором, що впливає на тяжкість перебігу ГП, частоту локальних і системних ускладнень.

Ключові слова: гострий панкреатит; ожиріння; ускладнення; синдром системної запальної відповіді; поліорганна недостатність.

\section{Abstract}

Introduction. Obesity constitutes the risk factor for an acute pancreatitis (AP) occurrence. Today the analysis, concerning unfavorable impact of obesity on the AP course severity and prognosis, is not used in practice for prognostication and the treatment tactics optimization. Objective. To analyze the impact of the obesity individual parameters on severity of the AP course.

Materials and methods. Prospective analysis of treatment of 30 patients, suffering an AP, was conducted. Ratio of the obesity individual parameters in accordance to CT data and the AP course severity, its local and systemic complications was investigated.

Results. Most significant correlation was established between the visceral fat area, electronic body mass index (BMI) and severity of the polyorgan insufficiency syndrome (POIS), the SIRS (systemic inflammatory response syndrome) duration, the local complications severity in accordance to Balthazar scale. Basing on the correlation analysis results there was established, that most profound influence on the treatment duration in stationary patients was caused by the SIRS duration, the POIS severity, and the CT index of severity in accordance to Balthazar. Basing on multivariate analysis, the only one parameter, influencing the stationary treatment duration in patient, is the SIRS duration, while other parameters, including individual parameters of obesity, did not impact this index. In obese patients the infectioning of the liquid accumulations and the necrosis foci were observed trustworthy more frequently, comparing with those in patients with excessive or normal body mass, but in them more frequently the pancreatic cysts occurrence formation was noted $(p<0,05)$. Trustworthy more frequent infectioning was observed in patients, suffering obesity, while investigation of the liquid accumulations and the necrosis foci infectioning. In obese patients the earlier infectioning of the liquid accumulations and the necrosis foci were observed $(p=0,006)$.

Conclusion. Obesity constitutes a factor, impacting the AP course severity, local and systemic complications rate.
\end{abstract}

Keywords: acute pancreatitis; obesity; complications; systemic inflammatory response syndrome; polyorgan insufficiency.

Ожиріння вважають фактором ризику виникнення ГП [1 - 4], при цьому особливе значення має розподіл жиру. Так, доведено, що вісцеральне ожиріння стійко корелює 3 метаболічними розладами, зокрема, гіперліпідемією, артеріальною гіпертензією, резистентністю до інсу- ліну [1]. Ожиріння сьогодні набуває рівня епідемії в західних країнах, і не випадково, що частота виникнення ГП також збільшується $[2,5,6]$.

Жирова тканина виконує функцію не лише депо енергіï, а й ендокринну функцію, виділяючи біологічно активні речовини - адипокі- ни. Вісцеральний жир продукує такі адипокіни, як лептин, фактор некрозу пухлин-альфа, інтерлейкін-6, що мають прозапальні властивості. Також існує думка, що, зважаючи на синтез цитокінів в жировій клітковині, у пацієнтів за вісцерального ожиріння виявляють гіперзапальний 
Таблиця 1. Характеристика пацієнтів, яким проведена КТ органів черевної порожнини

\begin{tabular}{|c|c|}
\hline Показник & Величина показника \\
\hline \multicolumn{2}{|l|}{ Стать } \\
\hline чоловіків & 24 \\
\hline жінок & 7 \\
\hline Вік, років & $43,6 \pm 13,8(20-69)^{*}$ \\
\hline Строки виконання КТ, діб & $18,5 \pm 10,8(7-60)^{*}$ \\
\hline \multicolumn{2}{|l|}{ Індивідуальні параметри ожиріння } \\
\hline $\mathrm{IMT}, \mathrm{kr} / \mathrm{M}^{2}$ & $29,9 \pm 5,8(19,3-40,6)^{*}$ \\
\hline elMT, $\mathrm{kr} / \mathrm{M}^{2}$ & $29,7 \pm 5,9(18,9-40,9)^{*}$ \\
\hline площа вісцерального жиру, мм² & $190,59 \pm 98,9 *$ \\
\hline площа підшкірного жиру, мм² & $194,8 \pm 116,03^{*}$ \\
\hline окружність живота, см & $101,01 \pm 12,2(82,4-126,5)^{*}$ \\
\hline ГП середньої тяжкості & 15 \\
\hline Тяжкий ГП & 15 \\
\hline Локальні ускладнення & 56 \\
\hline Системні ускладнення & 20 \\
\hline кТ-індекс тяжкості за Balthazar, балів & $6,9 \pm 2,32(3-10)^{*}$ \\
\hline СПОН (шкала Marshall), балів & $4,3 \pm 2,65(1-10)^{*}$ \\
\hline Тривалість SIRS, діб & $8,65 \pm 5,26(1-17)^{*}$ \\
\hline Тривалість лікування у стаціонарі, діб & $36,4 \pm 22,03(12-101)^{*}$ \\
\hline
\end{tabular}

фенотип, що зумовлює збільшення тяжкості SIRS при ГП, прогресування захворювання [7]. Зв'язок між ожирінням і SIRS досліджений у численних проспективних дослідженнях, встановлене достовірне підвищення рівня про- та протизапальних цитокінів у хворих при ожирінні порівняно з таким у пацієнтів за нормального індексу маси тіла (IMT) [8, 9]. Перебіг SIRS більш тяжкий у пацієнтів з ожирінням при ГП.

Механізм, за якого ожиріння підвищує ризик виникнення локальних та системних ускладнень, такий: ненасичені жирні кислоти, що виділяються внаслідок ліполізу інтрапанкреатичного жиру, підсилюють локальне пошкодження підшлункової залози при ГП, також індукована ненасиченими жирними кислотами ліпотоксичність може бути залучена у механізми СПОН [9]. Більша летальність при ГП у хворих з ожирінням пов'язана як $з$ вищим ризиком виникнення локальних та системних ускладнень, так і супутніх захворювань [10, 11].

Застосовують численні прогностичні шкали та системи оцінки тяжкості стану хворих на ГП, зокрема, Ranson, APACHE, Imrie, КТ індекс тяжкості за Balthazar [12]. За міжнародними рекомендаціями лікування ГП IАР/AРА (2013), для визначен- ня прогнозу використовують шкали: SIRS, MODS за Marshall, та КТ індекс тяжкості за Balthazar для локальних ускладнень ГП [10]. Потенційно, ожиріння - це важливий прогностичний показник у хворих на ГП, який сьогодні в стандартній оцінці тяжкості стану хворого не застосовують.

Проведений проспективний аналіз результатів лікування 30 хворих з приводу ГП. Критерії включення у дослідження: діагноз ГП встановлений під час госпіталізації хворого на основі наявності таких ознак: підвищення активності амілази в 3 рази і більше; наявність типового абдомінального болю та характерних ознак ГП за даними ультразвукового дослідження; проведення КТ органів черевної порожнини і порожнини таза. У дослідження не включали пацієнтів за наявності хронічного панкреатиту та тих, лікування яких було розпочате в інших лікувальних закладах.

Для оцінки ступеня ожиріння визначали такі параметри: IMT, еIMT, окружність живота, площу вісцерального та підшкірного жиру (за даними КТ). Для аналізу КТ-зображень використовували відкрите програм-

\section{МАТЕРІАЛИ I МЕТОДИ ДОСЛІДЖЕННЯ}

не забезпечення Osirix версії 3,9, за допомогою якого визначали площу жиру в стандартному аксіальному зрізі на рівні переходу міжхребцевого диска $\mathrm{L}_{\text {II }}$ в $\mathrm{L}_{\text {III }}$ хребець. Жирову тканину визначали за іiі щільністю, що відповідала від -30 до -190 од. Хаунсфілда. На цьому рівні визначали показники: площу тіла в аксіальному зрізі, площу підшкірного жиру, внутрішньочеревну площу (включаючи черевну порожнину та заочеревинний простір), площу вісцерального жиру.

Статистичний аналіз проводили за допомогою програмного забезпечення SPSS, v 20 (SPSS Inc., Chicago, IL.). Середні значення наведені 3 стандартним відхиленням і діапазоном значень. ANOVAтест застосований для порівняння середніх значень трьох і більше груп, t-test Student - для двох груп. Мультиваріантний аналіз використаний для оцінки впливу різних параметрів на тяжкість ГП та тривалість лікування хворого у стаціонаpi. Залежність між величинами оцінювали за допомогою коефіцієнту Пірсона.

Вік пацієнтів становив у середньому $(43,6 \pm 13,8)$ року. IMТ від 19,3

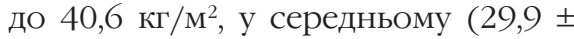
$5,8)$ кг $/ \mathrm{M}^{2}$, еІМТ - від 18,9 до 40,9 кг/

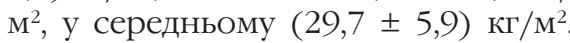
Клінічні дані та індивідуальні параметри ожиріння пацієнтів наведені у табл. 1.

Досліджували співвідношення індивідуальних параметрів ожиріння за даними КТ та тяжкості ГП, його локальних та системних ускладнень.

\section{РЕЗУЛЬТАТИ}

Досліджено кореляцію площі вісцерального та підшкірного жиру, тотальної площі жиру з еIMT, найсильніша кореляція встановлена 3 площею вісцерального жиру ( $\mathrm{r}=0,726$, $\mathrm{p}<0,001)$. Також виявлено кореляцію між окружністю живота і площею вісцерального жиру $(\mathrm{r}=0,876, \mathrm{p}$ $<0,001)$ та еIMT $(\mathrm{r}=0,714, \mathrm{p}<0,001)$. Найслабшу кореляцію спостерігали 3 площею підшкірного жиру (0,519, $\mathrm{p}=0,003)$. Таким чином, чим більша маса тіла пацієнта, тим більша площа вісцерального жиру. Параметри ожиріння мали суттеві гендерні відмінності. Чітко простежується тенденція до збільшення площі вісце- 


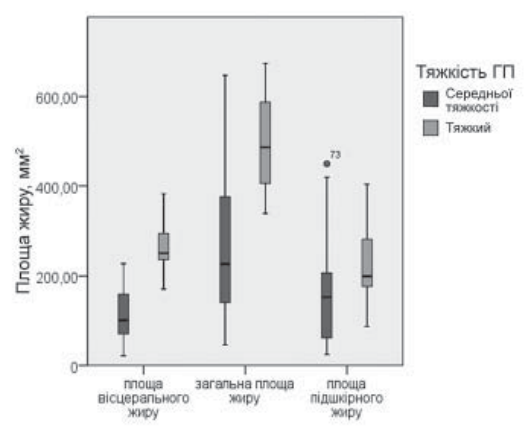

Рис 1.

Індивідуальні показники ожиріння залежно від ступеня тяжкості ГП.

рального жиру - у чоловіків (р < 0,001) і підшкірного жиру - у жінок $(\mathrm{p}=0,044)$.

Виявлений зв'язок між тяжкістю ГП та індивідуальними показниками кількості жиру. Площа вісцерального жиру у хворих за ГП середньої тяжкості становила (112,34 \pm $57,13)$ мм $^{2}$, за тяжкого ГП - $(268,83 \pm$ $62,27)$ мм² $^{2}$ частка вісцерального жиру від площі тіла - відповідно $(17,72$ $\pm 5,58)$ та $(29,73 \pm 5,66) \%(\mathrm{p}<0,001)$. Всі індивідуальні показники ожиріння, крім площі підшкірного жиру (p $=0,05)$, достовірно впливали на тяжкість ГП (рис. 1). У пацієнтів за тяжкого ГП площа вісцерального жиру та його відсоток від загальної площі жиру були достовірно більші у порівнянні з пацієнтами за ГП середньої тяжкості $(\mathrm{p}<0,001)$.

Вивчений вплив загальної площі жиру та площі вісцерального жиру на наявність і вид СПОН за допомогою тесту Дункана (ANOVA-test). Найбільшу різницю загальної площі жиру, площі вісцерального жиpy, еIMT та частки вісцерального жиру від площі тіла спостерігали в групі хворих за відсутності СПОН по-

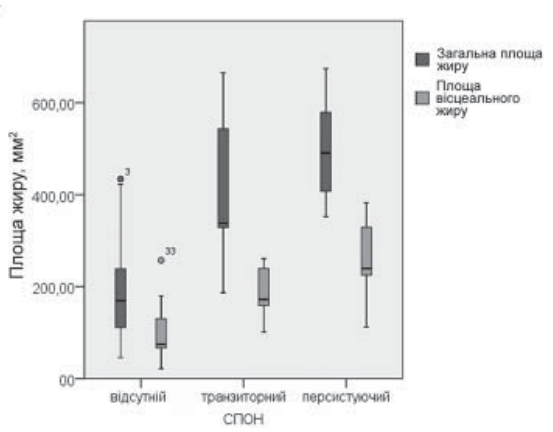

Рис 2.

Загальна площа жиру та площа вісцерального жиру за різних видів СПОН.

рівняно $з$ цими показниками за наявності транзиторного і персистуючого СПОН - відповідно (203,50 $\pm 133,09),(419,04 \pm 177,85)$ i $(507,14$ $\pm 102,01) \mathrm{MM}^{2}(\mathrm{p}<0,0001) ;(99,08 \pm$ $70,75),(194,50 \pm 91,28)$ i $(262,33 \pm$ $79,69) \mathrm{MM}^{2}(\mathrm{p}<0,0001) ;(23,28 \pm 2,54)$, $(30,11 \pm 3,12)$ i $(34,12 \pm 4,49) \kappa \Gamma / \mathrm{M}^{2}(\mathrm{p}$ $<0,0001)$; $(17,67 \pm 8,43),(23,08 \pm 4,65)$ i $(28,73 \pm 6,49) \%(p=0,003)$ (puc. 2). Таким чином, ожиріння впливає на перебіг і тяжкість СПОН.

Під час визначення зв'язку частки вісцерального жиру від загальної площі тіла за даними КТ в аксіальному зрізі та тяжкості СПОН за шкалою Маршала у строки до 48 год після госпіталізації хворого встановлений сильний позитивний зв'язок $(\mathrm{r}=$ $1, \mathrm{p}<0,0001$, рис. 3).

Кореляційний зв'язок між параметрами ожиріння та тяжкістю СПОН, віком хворих, КТ індексом тяжкості за Balthazar, тривалістю SIRS, тривалістю лікування хворого у стаціонарі наведений у табл. 2.

Найбільш значущу кореляцію спостерігали між площею вісцерального жиру і еІМТ та тяжкістю СПОН, тривалістю SIRS, тяжкістю локаль-

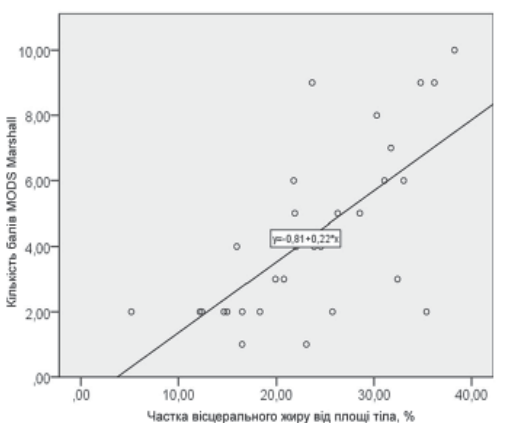

Рис. 3.

Кореляційно-регресійний аналіз зв'язку тяжкості СПОН за шкалою Маршала та частки вісцерального жиру від загальної площі тіла в аксіальному зрізі на рівні $L_{\text {, }}$ хребця.

них ускладнень за шкалою Balthazar (відповідно r = 0,727, $\mathrm{p}<0,0001$; $\mathrm{r}=$ $0,668, \mathrm{p}<0,0001 ; \mathrm{r}=0,549, \mathrm{p}=0,002)$.

За допомогою мультиваріантного регресійного аналізу досліджений вплив різних чинників на тяжкість ГП. Встановлено, що тяжкість СПОН за шкалою MODS, KT індекс тяжкості за Balthazar, тривалість SIRS, eIMT, загальна площа жиру та площа вісцерального жиру достовірно впливали на тяжкість ГП (відповідно $\mathrm{r}=$ $0,231, \mathrm{SE}=0,204, \mathrm{p}=0,07 ; \mathrm{r}=0,219, \mathrm{SE}$ $=0,191, \mathrm{p}=0,009 ; \mathrm{r}=0,257, \mathrm{SE}=0,230$, $\mathrm{p}=0,004 ; \mathrm{r}=0,672, \mathrm{SE}=0,660 ; \mathrm{r}=0,328$, $\mathrm{SE}=0,304, \mathrm{p}=0,001 ; \mathrm{r}=0,183, \mathrm{SE}=$ $0,154, p=0,018)$. В той же час, вплив віку та частки вісцерального жиру від площі тіла на тяжкість захворювання не встановлений (відповідно r $=0,015, \mathrm{SE}=-0,20, \mathrm{p}=0,52 ; \mathrm{r}=0,113, \mathrm{SE}$ $=0,081, \mathrm{p}=0,069$ )

За даними кореляційного аналізу, найбільше з досліджених параметрів на тривалість лікування хворого у стаціонарі впливали тяжкість СПОН, KT-індекс тяжкості за Balthazar, тривалість SIRS ( $\mathrm{r}=0,688, \mathrm{p}<0,0001$; $\mathrm{r}=$ $0,587, \mathrm{p}=0,001 ; \mathrm{r}=0,774, \mathrm{p}<0,0001)$. Проте, за даними мультиваріантно-

Таблиця 2. Кореляційний зв'язок між параметрами ожиріння та тяжкістю СпОН, віком хворих, КТ індексом тяжкості за Balthazar, тривалістю SIRS, тривалістю лікування хворого у стаціонарі

\begin{tabular}{|lccccc|}
\hline \multicolumn{1}{|c}{ Показник } & $\begin{array}{c}\text { Загальна площа } \\
\text { жиру, } \\
\mathrm{r}(\mathrm{p})\end{array}$ & $\begin{array}{c}\text { Площа } \\
\text { вісцерального } \\
\text { жиру, } \\
\mathrm{r}(\mathrm{p})\end{array}$ & $\begin{array}{c}\text { Площа підшкірного } \\
\text { жиру, } \\
\mathrm{r}(\mathrm{p})\end{array}$ & $\begin{array}{c}\text { вісцерального жиру } \\
\text { від площі тіла в } \\
\text { аксіальному зрізі, } \\
\mathrm{R}(\mathrm{p})\end{array}$ & $\begin{array}{c}\text { еІмт, } \\
\mathrm{r}(\mathrm{p})\end{array}$ \\
\hline Вік & $0,235(0,211)$ & $0,269(0,150)$ & $0,103(0,587)$ & $0,403(0,027)$ & $0,225(0,233)$ \\
\hline $\begin{array}{l}\text { KT iндекс тяжкості } \\
\text { за Balthazar }\end{array}$ & $0,478(0,008)$ & $0,509(0,004)$ & $0,301(0,106)$ & $0,474(0,008)$ & $0,549(0,002)$ \\
\hline MODS, Marshall & $0,642(<0,0001)$ & $0,727(<0,0001)$ & $0,372(0,043)$ & $0,673(<0,0001)$ & $0,727(<0,0001)$ \\
\hline Tривалість SIRS & $0,623(<0,0001)$ & $0,503(0,005)$ & $0,545(0,002)$ & $0,453(0,012)$ & $0,668(<0,0001)$ \\
\hline $\begin{array}{l}\text { Тривалість лікування } \\
\text { хворого у стаціонарі }\end{array}$ & $0,368(0,046)$ & $0,287(0,124)$ & $0,319(0,086)$ & $0,298(0,110)$ & $0,403(0,027)$ \\
\hline
\end{tabular}


го аналізу, єдиним параметром, що впливав на тривалість лікування хворого у стаціонарі, була тривалість SIRS ( $\mathrm{R}=0,987, \mathrm{SD}=0,907, \mathrm{p}=0,013)$, решта параметрів не впливали на цей показник, в тому числі індивідуальні параметри ожиріння.

За даними аналізу локальних ускладнень у хворих 3 ожирінням порівняно $з$ такими з збільшеною та нормальною масою тіла, встановлено, що у хворих з ожирінням достовірно частіше спостерігали інфікування скупчень рідини в поєднанні 3 інфікуванням вогнищ некрозу $(\mathrm{p}<$

\section{REFERENCES}

1. Hwang LC, Bai CH, Sun CA, Chen CJ. Prevalence of metabolically healthy obesity and its impacts on incidences of hypertension, diabetes and the metabolic syndrome in Taiwan. Asia Pacific Journal of Clinical Nutrition. 2012; 21(2):227-33.

2. Jones-Smith JC, Gordon-Larsen P, Siddiqi A, Popkin BM. Is the burden of overweight shifting to the poor across the globe? Time trends among women in 39 low- and middle-income countries (19912008). International Journal of Obesity. 2012 Sep 13;36:1114-20.

3. Armstrong ME, Lambert MI, Lambert EV. Secular trends in the prevalence of stunting, overweight and obesity among South African children (1994-2004). European Journal of Clinical Nutrition. 2011 Apr 20; 65:835-40.

4. Sadr-Azodi O, Orsini N, Andrén-Sandberg MD, Wolk A. Abdominal and total adiposity and the risk of acute pancreatitis: A PopulationBased Prospective Cohort Study. Am J Gastroenterol. 2012 Nov 13;108:133-9.

5. O'Leary P, O’Neill D, McLaughlin P, O’Neill S, Myers E, Maher MM, Redmond HP. Effects of abdominal fat distribution parameters on severity of acute pancreatitis. World Journal of Surgery. 2012 Jul; 36(7):1679-85.

6. Chen SM, Guang Su Xiong GS, Shu Ming WU. Is obesity an indicator of complications and mortality in acute pancreatitis? An updated meta-analysis. Journal of Digestive Diseases. 2012 May;13(5):24451. інфікування скупчень рідини і вогнищ некрозу.

Ожиріння впливає на тяжкість, перебіг і прогноз при ГП; зумовлює достовірне збільшення частоти системних та локальних ускладнень. Необхідний диференційований підхід до лікування хворих з приводу ГП з супутнім ожирінням. Раціональним вважаємо включення індивідуальних параметрів ожиріння, зокрема, площі вісцерального жиру, до КТоцінки тяжкості ГП.

7. Hong S, Qiwen B, Ying J, Wei A, Chaoyang T. Body mass index and the risk and prognosis of acute pancreatitis: a meta-analysis Inflammation. European Journal of Gastroenterology \& Hepatology. 2012 Dec;23(12):1136-43.

8. Gunjaca I, Zunic J, Gunjaca M, Kovac Z. Circulating cytokine levels in acute pancreatitis-model of SIRS/CARS can help in the clinical assessment of disease severity. Inflammation. 2012 Apr;35(2):758-63.

9. Premkumar R, Phillips AR, Petrov MS, Windsor JA. The clinical relevance of obesity in acute pancreatitis: targeted systematic reviews. Pancreatology. 2015 Jan-Feb;15(1):25-33.

10. Working group IAP/APA Acute Pancreatitis Guidelines. IAP/APA evidence-based guidelines for the management of acute pancreatitis. Pancreatology. 2013;13:1-15.

11. Dronov OI, Zadorozhna KO, Kovalska IO. Impact of obesity on complications and outcome of acute pancreatitis. Ibid. 2016;16(4):133-4.

12. Siplivyj VA, Dronov AI, Kon EV. Ocenka tjazhesti sostojanija hirurgicheskogo bolnogo. Kyiv: Naukovij svit; 2004.128 p. [In Russian]. 